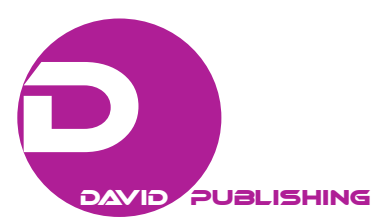

\title{
A Conceptual Framework for Commercial Property Price Indexes
}

\author{
Erwin Diewert \\ Professor, School of Economics, University of British Columbia, Vancouver B.C., \\ Canada, V6T 1 Z1 and the School of Economics, University of New South Wales, Sydney, Australia \\ Chihiro Shimizu \\ Professor, Institute of Real Estate Studies, National University of Singapore, 21 Heng \\ Mui Keng Terrace, \#04-02, Singapore 119613
}

\begin{abstract}
The paper studies the problems associated with the construction of price indexes for commercial properties that could be used in the System of National Accounts. Property price indexes are required for the stocks of commercial properties in the Balance Sheets of the country and related price indexes for the land and structure components of a commercial property are required in the Income Accounts of the country if the Multifactor Productivity of the Commercial Property Industry is calculated as part of the System of National accounts. The paper suggests a variant of the capitalization of the Net Operating Income approach to the construction of property price indexes and uses the one hoss shay or light bulb model of depreciation as a model of depreciation for the structure component of a commercial property.
\end{abstract}

Key Words: Commercial property price indexes, Net Operating Income, discounted cash flow, System of National Accounts, Balance Sheets, methods of depreciation, land and structure prices.

\section{Introduction}

Many of the property price bubbles experienced during the 20th century were triggered by steep increases and sharp decreases in commercial property prices. ${ }^{1}$ Given this, there is a need to construct commercial property price indexes but exactly how should these prices be measured? Since commercial property is highly heterogeneous compared to housing and the number of transactions is also much lower, it is extremely difficult to capture trends in this market. In addition, many countries have been experiencing large investments in commercial properties and in countries where the market has matured, depreciation and investments in improvements and renovations represents a substantial fraction of national output. But clear measurement methods for the treatment of these expenditures in the System of National Accounts are lacking. Given this, one may say that the economic value of commercial property in particular is one of the indicators that is most difficult to measure on a day-to-day basis and that statistical development related to this is one of the fields that has perhaps lagged the furthest behind. Indexes based on transaction prices for commercial properties have

\footnotetext{
${ }^{1}$ See Schreyer (2009b)[41] for material on real estate bubbles.

The authors thank David Fenwick, Jan de Haan Fran, cois Des Rosiers, Alice Nakamura, Alicia Rambaldi and Iqbal Syed for valuable comments.
} 
begun to appear in recent years, especially in the U.S. However, in many cases, these indexes are based on property appraisal prices. But appraisal prices need to be based on a firm methodology. Thus in this paper, we will briefly review possible appraisal methodologies and then develop in more detail what we think is the most promising approach.

In summary: the purpose of this paper is to present a framework for the organization of commercial property data into a form which would be suitable for national income accounting purposes and for the construction of property price indexes. Basically, the paper looks at the problems associated with the construction of output and input price indexes for periodic flow inputs as well as for the fixed assets used in the commercial property industry. Thus section 2 below looks at the problems associated with the construction of output indexes while section 3 studies the problems associated with the construction of variable input indexes such as intermediate input and labour indexes. Sections 4 and 5 present methodologies for constructing both stock and flow indexes for the fixed inputs used by commercial property firms, namely structures and the land that the structures sit on. Section 6 concludes.

It should be noted that the problems associated with constructing price indexes for commercial properties are more complex when the prices are required for national income accounting purposes as opposed for other purposes that simply require the determination of the joint value of commercial property structures and the associated land. ${ }^{2}$ For national income accounting purposes, the value of a commercial property needs to be decomposed into land and structure components, a problem that has been largely overlooked in the academic literature on commercial property price indexes. Most of the difficult problems associated with the construction of constant quality price indexes for the commercial property sector are associated with the land and structure inputs used by the sector.

Basically, three distinct methods have been used to construct commercial property price indexes for the fixed assets of a property firm:

- Methods based on commercial property sales transactions over time. Variants of this method include the repeat sales methodology and hedonic regression methods. ${ }^{3}$

- Methods based on observing published share prices for property stocks or REITs (Real Estate Investment Trusts) in order to estimate the asset value of the property. ${ }^{4}$

- Methods based on capitalizing the Net Operating Income (NOI) of a building trust. ${ }^{5}$

The major problem with the transactions based methods for determining the constant quality prices for commercial properties is that sales of commercial properties are very sparse. Thus hedonic and repeat sales

\footnotetext{
${ }^{2}$ Commercial property valuations may be required for mortgage applications and for the analysis of property bubbles where only the joint price of the structures and the associated land matters.

${ }^{3}$ Appraisers frequently base their estimates for the asset value of a commercial property on sales of similar properties during the same time period: "Real estate valuation is founded primarily on the use of comparable sales information." Andrew Baum and Neil Crosby $(2008 ; 17)$ [2]. This valuation method can be considered as a type of informal hedonic regression model. For a fairly comprehensive review of the hedonic regression methodology used in the valuation of residential properties, see de Haan and Diewert (2011) [8]. For comparisons of the hedonic regression and the repeat sales methodologies, see Diewert, Nakamura and Nakamura (2009) [21], Diewert (2010) [17] (2011) [18], Shimizu, Nishimura and Watanabe (2010) [43] and Deng, McMillen and Sing (2013) [9]. See Devaney and Diaz (2010) [10] for an application of the hedonic regression methodology to the commercial property context.

${ }^{4}$ Papers that use this methodology include Fisher, Geltner and Webb (1994) [26], Geltner (1997) [27], Geltner, Pollakowski, Horrigan and Case (2010) [28], Bokhari and Geltner (2012) [3] and Shimizu, Diewert, Nishimura and Watanabe (2013) [42].

${ }^{5}$ Methods of this type are discussed in some detail in Baum and Crosby (2008; 27) [2] and are labelled as discounted cash flow models or capitalization of income approaches. Our particular variant of this class of methods to be explained later can be regarded as a discounted cash flow model.
} 
methods, which can work well for constructing constant quality price indexes for residential properties, may not work well in the commercial property context due to the infrequency of sales of these properties.

Stock market based methods for determining the prices of commercial properties are subject to three problems:

- The stock market valuation of a commercial property REIT that has a constant portfolio of properties does not provide a constant quality price for the fixed assets in that portfolio due to the depreciation of the structures in the portfolio.

- For national income accounting purposes, a decomposition of the asset value of a REIT into its structure and land components is required and the stock market valuation cannot provide this breakdown.

- Stock market valuations will generally be too volatile for statistical agency purposes. The stock market price of a REIT will typically over react to daily news about macroeconomic events. ${ }^{6}$

Thus in our view, the most useful method for obtaining constant quality prices for commercial properties is the capitalization of net operating income method. We will present a variant of this method in some detail in sections 4 and 5 below. Our analysis will give practical advice on how statistical agencies could construct both stock and flow price indexes for commercial structures and the land that the structures sit upon.

A particular problem with existing methodologies for the capitalization of the NOI of a particular property in order to obtain estimates of the current asset value of the property is that they do not deal adequately with the problems raised by the depreciation of the structure over time. These difficulties were discussed by Dixon, Crosby and Law (1999) [22] and Crosby, Devaney and Law (2012) [6] and their papers contain extensive reviews of the depreciation literature as it applies to commercial properties. However, our suggested solution to these problems is quite different than the solutions presented in these publications. ${ }^{7}$

\section{The Construction of Output Price Indexes}

We consider the problems associated with constructing quarterly input and output price indexes for a particular commercial property in a single location. We assume that the property has $N$ sources of revenue and the quarter $t$ price for product $n=1,2, \ldots, N$ is $p_{n}^{t}$ and the corresponding quantity sold during the quarter is $q_{n}^{t}$. Before proceeding further, we need to discuss the exact meaning of the microeconomic prices and quantities if there are multiple transactions for say commodity $n$ within quarter $t$. In this case, it is natural to interpret $q_{n}^{t}$ as the total amount of commodity $n$ sold within quarter $t$. In order to conserve the value of transactions, it is necessary that $p_{n}^{t}$ be defined as a unit value ${ }^{8}$; i.e., $p_{n}^{t}$ must be equal to the value of transactions for commodity $n$ during quarter $t$ divided by the total quantity transacted, $q_{n}^{t}$. Thus define the revenue of the commercial property in quarter $t$ as:

$$
R^{t} \equiv \sum_{n=1}^{N} p_{n}^{t} q_{n}^{t} \equiv \mathbf{p}^{t} \cdot \mathbf{q}^{t}
$$

\footnotetext{
${ }^{6}$ However, an advantage of the share price method over the NOI method is that the former method may predict turning points in the property market in advance of the latter method since stock market valuations are forward looking, whereas Net Operating Income gives a snapshot of the property's current (or slightly backward looking) income generating abilities.

${ }^{7}$ Our method relies on a depreciation model discussed in the national income accounting literature.

${ }^{8}$ The early index number theorists Walsh $(1901 ; 96)$ [46], Fisher $(1922 ; 318)$ [25] and Davies (1924; 96) [7] all suggested unit values as the prices that should be inserted into an index number formula. This advice is followed in the Consumer Price Index Manual: Theory and Practice with the proviso that the unit value be a narrowly defined one; see the ILO (2004; 356) [31].
} 
where $\mathbf{p}^{t} \equiv\left(p_{1}^{t}, \ldots, p_{N}^{t}\right)$ is the quarter $t$ output price vector, $\mathbf{q}^{t} \equiv\left(q_{1}^{t}, \ldots, q_{N}^{t}\right)$ is the quarter $t$ output quantity vector and $\mathbf{p}^{t} \cdot \mathbf{q}^{t}$ denotes the inner product of these two vectors.

The outputs produced by an office or retail building will typically consist primarily of the rental or leasing of individual units of floor space. The total floor space leased or rented will generally be well below the total floor space of the building since some space will be taken up by hallways, utility rooms, caretaker and managerial offices. ${ }^{9}$ When measuring outputs, rented space is what counts but in section 5 when valuing the cost of the services provided by the basic building structure, it is total floor space that matters. In addition to leased office and retail space, the building may make additional revenues from renting parking spaces and other miscellaneous sources of revenues. ${ }^{10}$

If the revenue generating property leases (for commercial space in the building) are monthly or quarterly, there is no problem in determining quarterly revenues. However, if the leases extend longer than a quarter and there is a fixed payment at the beginning of the lease for the use of leased space that covers the entire leasing period, then this total lease payment has to be amortized into imputed quarterly payments over the life of the lease. There are various commercial accounting methods for accomplishing this amortization and the price statistician may have no choice but to use whatever amortization method was used in the quarterly statements of the property owner. However, if detailed information on the building leases is available, then one hoss shay amortization is a useful method that can be recommended. This method will be explained in section 4 below in the context of amortizing the cost of a building that lasts $L$ quarters after it is constructed. In the present output price context, the length of life $L$ is now interpreted as the length of the lease. ${ }^{11}$

The index number problem can be explained in the following manner. Consider the property's revenue ratio going from say quarter 0 to $1, R^{1} / R^{0}$. Index numbers attempt to decompose a value ratio for the two periods under consideration into a price change component $P$ times a quantity change component $Q$. Thus we look for two functions of $4 N$ variables, $P\left(\mathbf{p}^{0}, \mathbf{p}^{1}, \mathbf{q}^{0}, \mathbf{q}^{1}\right)$ and $Q\left(\mathbf{p}^{0}, \mathbf{p}^{1}, \mathbf{q}^{0}, \mathbf{q}^{1}\right)$ such that: ${ }^{12}$

$$
\frac{\mathbf{p}^{1} \cdot \mathbf{q}^{1}}{\mathbf{p}^{0} \cdot \mathbf{q}^{0}}=P\left(\mathbf{p}^{0}, \mathbf{p}^{1}, \mathbf{q}^{0}, \mathbf{q}^{1}\right) Q\left(\mathbf{p}^{0}, \mathbf{p}^{1}, \mathbf{q}^{0}, \mathbf{q}^{1}\right)
$$

It can be seen that if the price index function $P\left(\mathbf{p}^{0}, \mathbf{p}^{1}, \mathbf{q}^{0}, \mathbf{q}^{1}\right)$ has been determined, then the quantity

\footnotetext{
${ }^{9}$ However, an industrial building is typically leased to a single business and in this case, total floor space would coincide with rented floor space.

${ }^{10}$ For example, a building may derive revenues from a transmission tower on the top of the building.

${ }^{11}$ The amortization method is explained below by equations (13)-(16). If the lease payment is made at the beginning of quarter $t$ and the length of the lease is $L$ quarters, then $P_{0}^{t}$ in equation (13) can be interpreted as the total lease payment, $f^{t}$ is the quarter $t$ imputed revenue for the firm, $i_{t}$ is the expected quarterly inflation rate for the rental of space of the type under consideration, $r_{t}$ is the firm's opportunity cost of capital at the beginning of period $t$ and $\left(1+i_{t}\right)^{s} f^{t}$ is the imputed revenue for the space under consideration in quarter $t+s$ for $s=1,2, \ldots, L-1$.

${ }^{12}$ If $N=1$, then we define $P\left(p_{1}^{0}, p_{1}^{1}, q_{1}^{0}, q_{1}^{1}\right) \equiv p_{1}^{1} / p_{1}^{0}$ and $Q\left(p_{1}^{0}, p_{1}^{1}, q_{1}^{0}, q_{1}^{1}\right) \equiv q_{1}^{1} / q_{1}^{0}$, the single price ratio and the single quantity ratio respectively. In the case of a general $N>1$, we think of $P\left(p_{1}^{0}, p_{1}^{1}, q_{1}^{0}, q_{1}^{1}\right)$ as being a weighted average of the price ratios $p_{1}^{1} / p_{1}^{0}, p_{2}^{1} / p_{2}^{0}, \ldots, p_{N}^{1} / p_{N}^{0}$. Thus we interpret $P\left(p_{1}^{0}, p_{1}^{1}, q_{1}^{0}, q_{1}^{1}\right)$ as an aggregate price ratio, $P^{1} / P^{0}$, where $P^{t}$ is the aggregate price level for period $t$ for $t=0,1$.
} 
index $Q\left(\mathbf{p}^{0}, \mathbf{p}^{1}, \mathbf{q}^{0}, \mathbf{q}^{1}\right)$ can be residually determined using equation (2). If the functional form for $P\left(\mathbf{p}^{0}, \mathbf{p}^{1}, \mathbf{q}^{0}, \mathbf{q}^{1}\right)$ is known, then we can use (2) to determine the period 0 and 1 aggregate price levels, $P^{0}$ and $P^{1}$ respectively, and the period 0 and 1 aggregate quantity (or volume) levels, $Q^{0}$ and $Q^{1}$ respectively, as follows:

$$
P^{0} \equiv 1 ; P^{1} \equiv P\left(\mathbf{p}^{0}, \mathbf{p}^{1}, \mathbf{q}^{0}, \mathbf{q}^{1}\right) ; Q^{0} \equiv \mathbf{p}^{0} \cdot \mathbf{q}^{0} ; Q^{1} \equiv \frac{\mathbf{p}^{1} \cdot \mathbf{q}^{1}}{P\left(\mathbf{p}^{0}, \mathbf{p}^{1}, \mathbf{q}^{0}, \mathbf{q}^{1}\right)} .
$$

Thus once the functional form for the price index $P\left(\mathbf{p}^{0}, \mathbf{p}^{1}, \mathbf{q}^{0}, \mathbf{q}^{1}\right)$ is determined (and detailed price and quantity data are available for the two quarters), aggregate output price and quantity levels for the two quarters under consideration can be determined using the definitions in (3).

There are four main approaches to the determination of the functional form for a price index $P\left(\mathbf{p}^{0}, \mathbf{p}^{1}, \mathbf{q}^{0}, \mathbf{q}^{1}\right)$ that compares the prices (and associated quantities) between two periods:

Fixed basket and averages of fixed basket approaches;

- The test or axiomatic approach;

- The stochastic approach and

- The economic approach.

These four approaches are explained in detail elsewhere. ${ }^{13}$

There are two main functional forms for the price index that are used by statistical agencies as ideal target indexes: the Fisher ideal price index $P_{F}$ and the Törnqvist-Theil price index $P_{T}$. Before defining these two indexes, it is useful to define some other indexes that are frequently used by statistical agencies.

One of the earliest approaches to defining a price index the fixed basket approach. In this approach, we are given a "representative" basket of commodities that is defined by the positive quantity vector $\mathbf{q}$. Given the price vectors for periods 0 and $1, \mathbf{p}^{0}$ and $\mathbf{p}^{1}$ respectively, we can calculate the cost of purchasing this same basket in the two periods, $\mathbf{p}^{0} \cdot \mathbf{q}$ and $\mathbf{p}^{1} \cdot \mathbf{q}$. Then the ratio of these costs is a very reasonable indicator of pure price change over the two periods under consideration, provided that the basket vector $\mathbf{q}$ is "representative". Thus define the Lowe (1823) [37] price index, $P_{L o}$, as follows:

$$
P_{L o}\left(\mathbf{p}^{0}, \mathbf{p}^{1}, \mathbf{q}\right) \equiv \frac{\mathbf{p}^{1} \cdot \mathbf{q}}{\mathbf{p}^{0} \cdot \mathbf{q}} .
$$

As time passed, economists and price statisticians demanded a bit more precision with respect to the specification of the basket vector $\mathbf{q}$. There are two natural choices for the reference basket: the period 0 commodity vector $\mathbf{q}^{0}$ or the period 1 commodity vector $\mathbf{q}^{1}$. These two choices lead to the Laspeyres (1871) [36] price index $P_{L}$ defined by (5) and the Paasche (1874) [38] price index $P_{P}$ defined by (6): ${ }^{14}$

$$
P_{L}\left(\mathbf{p}^{0}, \mathbf{p}^{1}, \mathbf{q}^{0}, \mathbf{q}^{1}\right) \equiv \frac{\mathbf{p}^{1} \cdot \mathbf{q}^{0}}{\mathbf{p}^{0} \cdot \mathbf{q}^{0}}=\sum_{n=1}^{N} s_{n}^{0}\left(p_{n}^{1} / p_{n}^{0}\right) ;
$$

\footnotetext{
${ }^{13}$ See Diewert (2012) [19] or the Consumer Price Index Manual, ILO/IMF/OECD/UNECE/Eurostat/The World Bank (2004; 263-327) [31]. For brevity, in the future, we will refer to the CPI Manual as ILO (2004).

${ }^{14}$ Note that $P_{L}\left(\mathbf{p}^{0}, \mathbf{p}^{1}, \mathbf{q}^{0}, \mathbf{q}^{1}\right)$ does not actually depend on $\mathbf{q}^{1}$ and $P_{P}\left(\mathbf{p}^{0}, \mathbf{p}^{1}, \mathbf{q}^{0}, \mathbf{q}^{1}\right)$ does not actually depend on $\mathbf{q}^{0}$.
} 


$$
P_{P}\left(\mathbf{p}^{0}, \mathbf{p}^{1}, \mathbf{q}^{0}, \mathbf{q}^{1}\right) \equiv \frac{\mathbf{p}^{1} \cdot \mathbf{q}^{1}}{\mathbf{p}^{0} \cdot \mathbf{q}^{1}}=\left[\sum_{n=1}^{N} s_{n}^{1}\left(p_{n}^{1} / p_{n}^{0}\right)^{-1}\right]^{-1}
$$

where the period $t$ expenditure share on commodity $n, s_{n}^{t}$, is defined as $p_{n}^{t} q_{n}^{t} / \mathbf{p}^{t} \cdot \mathbf{q}^{t}$ for $n=1, \ldots, N$ and $t=0,1$. Thus the Laspeyres price index $P_{L}$ can be written as a base period expenditure share weighted average of the $N$ price ratios (or price relatives), $p_{n}^{1} / p_{n}^{0} .{ }^{15}$ The last equation in (6) shows that the Paasche price index $P_{P}$ can be written as a period 1 (or current period) expenditure share weighted harmonic average of the $N$ price ratios. ${ }^{16}$

The problem with these index number formulae is that they are equally plausible but in general, they will give different answers. This suggests that if we require a single estimate for the price change between the two periods, then we should take some sort of evenly weighted average of the two indexes as our final estimate of price change between periods 0 and 1 . An examples of a symmetric average is the geometric mean, which leads to the Fisher (1922)[25] ideal index, $P_{F}$, defined as

$$
P_{F}\left(\mathbf{p}^{0}, \mathbf{p}^{1}, \mathbf{q}^{0}, \mathbf{q}^{1}\right) \equiv\left[P_{L}\left(\mathbf{p}^{0}, \mathbf{p}^{1}, \mathbf{q}^{0}, \mathbf{q}^{1}\right) P_{P}\left(\mathbf{p}^{0}, \mathbf{p}^{1}, \mathbf{q}^{0}, \mathbf{q}^{1}\right)\right]^{1 / 2} .
$$

Another useful functional form for the target price index is the Törnqvist-Theil index $P_{T}$. Theil (1967; 137)[44] provided a strong justification for the use of this index from the perspective of the stochastic or descriptive statistics approach to index number theory. Theil's measure of overall logarithmic price change is defined as follows:

$$
\ln P_{T}\left(\mathbf{p}^{0}, \mathbf{p}^{1}, \mathbf{q}^{0}, \mathbf{q}^{1}\right) \equiv \sum_{n=1}^{N} \frac{s_{n}^{0}+s_{n}^{1}}{2} \ln \left(p_{n}^{1} / p_{n}^{0}\right)
$$

Exponentiating the right hand side of (8) provides a formula for $P_{T}\left(\mathbf{p}^{0}, \mathbf{p}^{1}, \mathbf{q}^{0}, \mathbf{q}^{1}\right) .^{17}$

The Fisher index $P_{F}$ receives a strong justification as a target index from the perspectives of the basket, axiomatic and economic approaches to index number theory while the Törnqvist-Theil index $P_{T}$ receives a strong justification from the perspectives of the axiomatic, stochastic and economic approaches to index number theory. ${ }^{18}$ Thus choosing between these two alternative indexes is difficult but fortunately, using time series data, these two index formulae give very similar results and so typically, it will not matter which of these two indexes is chosen. ${ }^{19}$

The above material dealt with aggregating revenue information on multiple sources of revenue from the same building. This information can be aggregated over multiple buildings in the same location and in the same industry to form an industry output price index using the two stage aggregation procedures that are commonly

\footnotetext{
${ }^{15}$ This result is due to Walsh (1901; 428 and 539) [46].

${ }^{16}$ This expenditure share and price ratio representation of the Paasche index is described by Walsh $(1901 ; 428)[46]$ and derived explicitly by Fisher $(1911 ; 365)$ [24].

${ }^{17}$ The U.S. Bureau of Labor Statistics uses this index number formula as its target Consumer Price Index at higher levels of aggregation.

${ }^{18}$ See the ILO (2004) [31].

${ }^{19}$ Diewert $(1978 ; 888)[11]$ showed that $P_{T}\left(\mathbf{p}^{0}, \mathbf{p}^{1}, \mathbf{q}^{0}, \mathbf{q}^{1}\right)$ approximates $P_{F}$ to the second order around an equal price and quantity point. However, Diewert's results assumed that all prices and quantities were positive.
} 
used in the construction of a Producer Price Index. ${ }^{20}$ Typically, commercial buildings in a particular location are classified into three groups:

- Offices;

- Retail sales and

- Industrial (or factories).

Buildings could be further subdivided according to the type of construction and other characteristics.

We conclude this section with a discussion of the problems raised by vacancies; i.e., for some quarters, some parts of the building may be temporarily vacant and thus for these components $n$ of the building's revenue stream for quarter $t$, it may be the case that $p_{n}^{t}$ equals 0 . These zero components can cause the Törnqvist-Theil index $P_{T}$ to be ill-defined since the log of 0 is infinite. ${ }^{21}$ The solution to this problem is to note that typically, the individual output quantities $q_{n}^{t}$ are constant ${ }^{22}$ and so we have $q_{n}^{0}=q_{n}^{1}$ for $n=1,2, \ldots, N$, irrespective of whether all units are rented for the two periods or not. Thus under these conditions, the Laspeyres, Paasche and Fisher output price indexes reduce to the Lowe index, $P_{L o}\left(\mathbf{p}^{0}, \mathbf{p}^{1}, \mathbf{q}\right) \equiv \mathbf{p}^{1} \cdot \mathbf{q} / \mathbf{p}^{0} \cdot \mathbf{q}$ where $\mathbf{q}$ is the common quantity vector for the two periods under consideration. Under these conditions, letting $P$ be either $P_{L}, P_{P}$ or $P_{F}$, we find using definitions (3) that the price and quantity levels for quarters 0 and 1 become:

$$
P^{0} \equiv 1 ; P^{1} \equiv P\left(\mathbf{p}^{0}, \mathbf{p}^{1}, \mathbf{q}^{0}, \mathbf{q}^{1}\right)=\frac{R^{1}}{R^{0}}=\frac{\mathbf{p}^{1} \cdot \mathbf{q}^{1}}{\mathbf{p}^{0} \cdot \mathbf{q}^{0}} ; Q^{0} \equiv \mathbf{p}^{0} \cdot \mathbf{q}^{0} ; Q^{1} \equiv \mathbf{p}^{0} \cdot \mathbf{q}^{0}=Q^{0} .
$$

Thus the price index $P\left(\mathbf{p}^{0}, \mathbf{p}^{1}, \mathbf{q}^{0}, \mathbf{q}^{1}\right)$ collapses to the revenue ratio, $R^{1} / R^{0}$ if we use the Laspeyres, Paasche or Fisher index number formula. Hence our solution to the vacancy problem is simple: use the Fisher formula $P_{F}$ and not the index $P_{T}$ in order to form a commercial property output price index.

It should be noted that our suggested national income accounting treatment of commercial property revenues differs somewhat from the treatment used by commercial property appraisers. Appraisers impute a "normal" rent for vacant suites in the building and add it to actual rent. They then reduce this imputed total rent by one minus a "normal" vacancy rate and they use this adjusted rent as their estimate of Net Operating Revenues for the building in the period under consideration. ${ }^{23}$ However, this type of imputation would typically not be made for national accounting purposes where revenues are taken to be actual period $t$ operating revenues for the production unit, not imputed revenues. It can be seen that, typically, appraised operating income will be smoother than actual operating revenues, since vacancies are not uniform over time.

We turn our attention to the construction of (non capital) input indexes for a commercial property.

\section{The Construction of Variable Input Price Indexes}

In this section, we focus on nondurable variable inputs that have well defined price and quantity components and that are used by the commercial property firm in quarters $t=0,1$. We assume that there are

\footnotetext{
${ }^{20}$ See the IMF/ILO/OECD/UNECE/Eurostat/The World Bank (2004) [31].

${ }^{21}$ The second alternative formulae for the Laspeyres and Paasche indexes defined by (5) and (6) can also become ill-defined if some prices are zero.

${ }^{22}$ If renovations occur while the unit is vacant, then there will be a quality adjustment problem.

${ }^{23}$ See Baum and Crosby $(2008 ; 67)$ [2].
} 
$M$ such variable inputs. ${ }^{24}$ Denote the quarter $t$ unit value price of input $m$ by $p_{I m}^{t}$ and the corresponding total quantity purchased during the quarter by $q_{I m}^{t}$ for $m=1,2, \ldots, M{ }^{25}$ Examples of these nondurable inputs include the following:

- Inputs used to heat the building such as fuel oil, coal and natural gas;

- Electricity inputs;

- Telecommunication inputs;

- Cleaning supplies;

- Janitorial, maintenance and repair inputs;

- Security and caretaker services and

- Managerial and legal services inputs.

In the standard System of National Accounts and in Multifactor Productivity Accounts, ${ }^{26}$ these nondurable inputs are further classified as intermediate inputs or as labour inputs. The last three classes of inputs listed above could be listed as labour inputs if the type of service rendered is provided by an employee of the commercial property firm. Alternatively, these three types of input could be classified as intermediate inputs if the type of service is contracted out.

The construction of an input price index for the $M$ classes of input proceeds in a manner that is entirely analogous to our discussion of an output price index in the previous section. Thus the property's quarter $t$ variable input cost $C^{t}$ is defined as follows:

$$
C^{t} \equiv \sum_{m=1}^{M} p_{I m}^{t} q_{I m}^{t} \equiv \mathbf{p}_{I}^{t} \cdot \mathbf{q}_{I}^{t}
$$

where $\mathbf{p}_{I}^{t} \equiv\left(p_{I 1}^{t}, \square, p_{I M}^{t} \quad\right.$ denotes the quarter $t$ variable input price vector, $\mathbf{q}_{I}^{t} \equiv\left(q_{I 1}^{t}, \square, q_{I M}^{t} \quad\right.$ is the corresponding quarter $t$ variable input quantity vector and $\mathbf{p}_{I}^{t} \cdot \mathbf{q}_{I}^{t}$ denotes the inner product of these two vectors.

Consider the property's variable cost ratio going from say quarter 0 to $1, C^{1} / C^{0}$. As in the previous section, we decompose this value ratio for the two quarters under consideration into an input price change component $P_{I}$ times an input quantity change component $Q_{I}$. Thus we look for two functions of $4 M$ variables, $P_{I}\left(\mathbf{p}^{0}, \mathbf{p}^{1}, \mathbf{q}^{0}, \mathbf{q}^{1}\right)$ and $Q_{I}\left(\mathbf{p}^{0}, \mathbf{p}^{1}, \mathbf{q}^{0}, \mathbf{q}^{1}\right)$ such that:

$$
\frac{\mathbf{p}_{I}^{1} \cdot \mathbf{q}_{I}^{1}}{\mathbf{p}_{I}^{0} \cdot \mathbf{q}_{I}^{0}}=P_{I}\left(\mathbf{p}_{I}^{0}, \mathbf{p}_{I}^{1}, \mathbf{q}_{I}^{0}, \mathbf{q}_{I}^{1}\right) Q_{I}\left(\mathbf{p}_{I}^{0}, \mathbf{p}_{I}^{1}, \mathbf{q}_{I}^{0}, \mathbf{q}_{I}^{1}\right) .
$$

It can be seen that if the price index function $P_{I}\left(\mathbf{p}_{I}^{0}, \mathbf{p}_{I}^{1}, \mathbf{q}_{I}^{0}, \mathbf{q}_{I}^{1}\right)$ has been determined, then the quantity index $Q_{I}\left(\mathbf{p}_{I}^{0}, \mathbf{p}_{I}^{1}, \mathbf{q}_{I}^{0}, \mathbf{q}_{I}^{1}\right)$ can be residually determined using equation (11). If the functional form for $P_{I}\left(\mathbf{p}_{I}^{0}, \mathbf{p}_{I}^{1}, \mathbf{q}_{I}^{0}, \mathbf{q}_{I}^{1}\right)$ is known, then we can use (11) to determine the quarter 0 and 1 aggregate input price

\footnotetext{
${ }^{24}$ Using national income accounting terminology, the variables inputs in this section refer to intermediate inputs and labour inputs.

${ }^{25}$ We have added the subscript $I$ to the prices and quantities in order to distinguish input prices and quantities for the output prices and quantities considered in the previous section.

${ }^{26}$ For explanations on how Multifactor Productivity Accounts can be constructed, see Jorgenson and Griliches (1967) [35], Christensen and Jorgenson (1973) [5], Diewert (1980) [12] (1992) [13] and Schreyer (2001) [39] (2009a) [40].
} 
levels, $P_{I}^{0}$ and $P_{I}^{1}$ respectively, and the quarter 0 and 1 aggregate input quantity (or volume) levels, $Q_{I}^{0}$ and $Q_{I}^{1}$ respectively, as follows:

$$
P_{I}^{0} \equiv 1 ; P_{I}^{1} \equiv P_{I}\left(\mathbf{p}_{I}^{0}, \mathbf{p}_{I}^{1}, \mathbf{q}_{I}^{0}, \mathbf{q}_{I}^{1}\right) ; Q_{I}^{0} \equiv \mathbf{p}_{I}^{0} \cdot \mathbf{q}_{I}^{0} ; Q_{I}^{1} \equiv \frac{\mathbf{p}_{I}^{1} \cdot \mathbf{q}_{I}^{1}}{P_{I}\left(\mathbf{p}_{I}^{0}, \mathbf{p}_{I}^{1}, \mathbf{q}_{I}^{0}, \mathbf{q}_{I}^{1}\right)} .
$$

As in the previous section, the four major approaches to index number theory that have been considered in the literature to date suggest that the Fisher or Törnqvist-Theil functional forms defined earlier by (7) and (8) would be good choices for $P_{I}\left(\mathbf{p}_{I}^{0}, \mathbf{p}_{I}^{1}, \mathbf{q}_{I}^{0}, \mathbf{q}_{I}^{1}\right)$.

The problem of zero purchases of a particular input during one of the two periods under consideration needs to be addressed. ${ }^{27}$ We cannot use the solution to this problem that was used in the previous section because quantities of variable inputs are generally not constant across periods. To explain our suggested solution to the problem of zero purchases of an input during one period, we suppose $q_{m}^{0}$ units of a particular input are purchased in quarter 0 at price $p_{m}^{0}$ but no units of the input are purchased in quarter 1 . Thus it is clear that we can set $q_{m}^{1}$ equal to 0 but if we set $p_{m}^{1}$ equal to zero as well, our preferred Fisher and Törnqvist-Theil input indexes can generate anomalous results. In order to obtain stable input indexes over time, it is best to impute a positive price for the missing price, $p_{m}^{1}$. There are at least three possible choices for this imputation exercise: ${ }^{28}$

- Carry forward the price of the previous period; i.e., set $p_{m}^{1}$ equal to the observed price $p_{m}^{0}$ for the product $m$ in quarter 0 .

- Collect a price for the same product in quarter 1 . Thus if a quantity of a particular type of cleaning fluid was purchased by the firm in quarter 0 but not purchased in period 1 , a price for the same product is collected for period 1 .

- Assume that the rate of price change for product $m$ going from quarter 0 to 1 is the same as the rate of change of an available price index for a similar product or class of products. Thus suppose the level of a statistical agency price index for cleaning fluids is $P_{\mathrm{CF}}^{0}$ in quarter 0 and $P_{\mathrm{CF}}^{1}$ in quarter 1 , then the imputed price for product $m$ in quarter $1, p_{m}^{1}$, is set equal to $p_{m}^{0}\left[P_{\mathrm{CF}}^{1} / P_{\mathrm{CF}}^{0}\right]$.

The first method is not recommended if the inflation rate for product $m$ is high or very variable. ${ }^{29}$ The second method is a preferred method but it may be very costly to obtain the missing price quote from the marketplace. ${ }^{30}$ The third method will generally be satisfactory but of course, price indexes by product category must be available.

The above discussion has focussed on nondurable variable inputs for which (at least in principle) it is possible to obtain period by period unit value prices and the corresponding period by period quantities

\footnotetext{
${ }^{27}$ If the input $m$ is not purchased in both quarters 0 and 1 , then this input can simply be omitted in the list of inputs and normal index number theory is applied to the remaining commodities.

${ }^{28}$ Additional imputation methods are considered in Diewert (1980; 498-501)[12] and in Feenstra and Diewert (2001) [23].

${ }^{29}$ In periods of high or moderate inflation, the carry forward method of imputation will tend to understate input cost inflation over the periods where the input is not purchased but then the index will jump up when the input is finally repurchased.

${ }^{30} \mathrm{We}$ are essentially assuming that the price statistician has access to building level data on revenues and costs, where the costs are listed by transaction. In many cases, only quarterly accounting data will be available and costs will generally be decomposed only by a few product categories and while values by category might be available, average prices by category may not be available.
} 
purchased for the commercial property under consideration. However, there are three additional periodic input costs for which there are values but no obvious breakdown into price and quantity components. These three classes of value only nondurable variable input costs are as follows:

- Quarterly property tax payments, say $C_{\mathrm{PT}}^{t}$ for period $t$;

- Quarterly business income tax payments, say $C_{\mathrm{IT}}^{t}$ for period $t$ and

- Quarterly property insurance payments, say $C_{\mathrm{PI}}^{t}$ for period $t$.

These costs need to be decomposed into price and quantity components so that the real output and input of the Commercial Property sector can be computed for national income accounting purposes. We will defer the problems associated with these decompositions until we have studied the problems associated with costing out the contribution of the building or structure and of the land that the structure sits on. Thus in the following section, we study how stock and flow price indexes for the building can be constructed and then in the next section, we show how stock and flow price indexes for the plot area can be constructed. ${ }^{31}$

\section{The Construction of Stock and Flow Prices for the Commercial Building}

In this section, we address the problem of pricing the services the building provides in each period. This is a flow of services price but a stock price is also required; i.e., we require an estimate of the market value for the structure at the beginning of each accounting period and a decomposition of this value into a price and quantity component. ${ }^{32}$ Unfortunately, constructing price indexes for a durable input is a much more difficult task than constructing prices for outputs and variable inputs because imputations are required in order to construct the stock and flow prices for a durable input. The problem is that a market price for the building can only be observed at the time the building is constructed when it is possible to determine the construction cost. ${ }^{33}$ Allocating this construction cost across the useful lifetime of the building is a fundamental problem of accounting. There is no universally accepted single solution to this intertemporal cost allocation problem. In this section, we will suggest a possible method for solving this problem but the reader should keep in mind that other methods may be equally appropriate.

Capital theory ${ }^{34}$ suggests that the value of a durable input (or asset) at a point in time is equal to its expected discounted stream of flow returns. We will formalize this suggestion in (13) below. Let $P_{0}^{t}$ be the asset value of a newly constructed building at the beginning of quarter $t$ and suppose that the expected life of the structure is $L$ quarters. Suppose also that the cash flow that can be attributed to the services provided by the new structure in quarter $t$ is $f_{0}^{t}$. Now undertake a mental experiment and suppose that the same structure

\footnotetext{
${ }^{31}$ There is one additional cost category associated with a commercial property that needs to be taken into account and this category is period by period capital expenditures, $C_{\mathrm{CE}}^{t}$, on the property. We will deal with these expenditures in the following section.

${ }^{32}$ This information is required for the construction of the Balance Sheets for the commercial property sector of the economy. The value of the flow of structure services (and the decomposition of this value flow into price and quantity components) is also required in the System of National Accounts in order to construct estimates of the Multifactor Productivity growth of the commercial property sector.

${ }^{33}$ One might think that a market price could be observed when a building is sold but typically, the sale price includes not only the structure but the land that the structure sits on and hence an imputation must be made in order to decompose the sale price into structure and land components.

${ }^{34}$ Walras (1954) [45] (first edition published in 1874) was one of the earliest economists to state that capital stocks are demanded because of the future flow of services that they render. For background material on capital theory and production theory, see Jorgenson (1963) [33] (1989) [34], Christensen and Jorgenson (1969) [4], Diewert (1980) [12] (2005) [16], Hulten (1990) [30], Diewert and Lawrence (2000) [20] and Schreyer (2001) [39] (2009a) [40].
} 
is $n$ quarters older at the beginning of quarter $t$ (where $1 \leq n \leq L-1$ ) and its asset value is $P_{n}^{t}$, where $P_{n}^{t}<P_{0}^{t} \quad$ since an older asset has a smaller number of periods left in its useful life and hence will be worth less than a brand new asset. Suppose that the cash flow that can be attributed to the services provided by the $n$ quarters old structure in period $t$ is $f_{n}^{t}$ where $f_{n}^{t} \leq f_{0}^{t}$ for $n=1,2, \ldots, L-1{ }^{35}$ Finally, suppose that the firm that owns the building faces the nominal quarterly interest rate (cost of financial capital) $r_{t}$ at the beginning of period $t^{36}$ and that value of building structure services is expected to rise at the quarterly inflation rate $i_{t}$. Then capital theory suggests that the value of the new structure at the beginning of quarter $t$, $P_{0}^{t}$, should be equal to the following sum of discounted expected cash flows: ${ }^{37}$

$$
P_{0}^{t}=f_{0}^{t}+\gamma_{t} f_{1}^{t}+\left(\gamma_{t}\right)^{2} f_{2}^{t}+\cdots+\left(\gamma_{t}\right)^{L-1} f_{L-1}^{t}
$$

where the quarter $t$ discount factor $\gamma_{t}$ is defined as follows:

$$
\gamma_{t} \equiv \frac{1+i_{t}}{1+r_{t}}
$$

Under the same set of assumptions, capital theory suggests that the value of a similar structure that is $n$ quarters old at the beginning of period $t, P_{n}^{t}$, should be equal to the following sum of discounted expected cash flows:

$$
P_{n}^{t}=f_{n}^{t}+\gamma_{t} f_{n+1}^{t}+\left(\gamma_{t}\right)^{2} f_{n+2}^{t}+\cdots+\left(\gamma_{t}\right)^{L-1-n} f_{L-1}^{t} ; \quad n=1,2, \ldots, L-1
$$

In order to value the flow of structure services in the SNA for the commercial property under consideration, we require estimates for the $f_{n}^{t}$ for each quarter $t$ and for all ages $n$ of the structure for $n=0,1,2, \ldots, L-1$. In order to construct balance sheet estimates in the SNA for the assets of the commercial property sector, we require estimates for the $P_{n}^{t}$ for each quarter $t$ and for all ages $n$ of the structure for $n=0,1,2, \ldots, L-1$. Obviously, this is a rather daunting task. In order to construct a practical method for estimating these prices, we need to make additional assumptions.

In order to simplify the above general model of asset valuation, we will make a further assumption; namely, that the flow of building services by age of the building is constant over the useful life of the building. ${ }^{38}$ This assumption seems to be a reasonable one: basically the services provided by the structure are

\footnotetext{
${ }^{35}$ For $n \geq L, f_{n}^{t}=0$ since the structure is abandoned or demolished after delivering structure services for $L$ quarters.

${ }^{36}$ Conceptually, $r_{t}$ is equal to a gross rate of return that is high enough to cover business income taxes and pay investors a rate of return that will induce them to invest in the building. Thus business income taxes are folded into this rate of return.

${ }^{37}$ See Diewert (2005; 480-487) [16] for additional material on this model. The quarter $t$ cash flow for a building that is $n$ quarters old, $f_{n}^{t}$, can be interpreted as a quarter t imputed rental price for the building of the type under consideration that is $n$ quarters old.

${ }^{38}$ We hope to implement a more general depreciation model in future work.
} 
the same quarter by quarter over the useful life of the asset. ${ }^{39}$ This assumption means that all of the quarter $t$ flow prices for buildings of the type under consideration by age $n, f_{n}^{t}$, are equal to the quarter $t$ flow of services of a new building $f_{0}^{t}$. Thus we have:

$$
f^{t} \equiv f_{0}^{t}=f_{1}^{t}=\cdots=f_{L-1}^{t} .
$$

This is known as the light bulb or one hoss shay model of depreciation. ${ }^{40}$ Upon substituting equations (16) into (13), we obtain the following relationship between the stock and flow prices for a new building at the beginning of quarter $t$ :

$$
\begin{gathered}
P_{0}^{t}=f^{t}\left[1+\gamma_{t}+\left(\gamma_{t}\right)^{2}+\cdots+\left(\gamma_{t}\right)^{L-1}\right] \\
=f^{t} \cdot \frac{1-\left(\gamma_{t}\right)^{L}}{1-\gamma_{t}}
\end{gathered}
$$

where the second equation follows if $\gamma_{t} \equiv\left[1+i_{t}\right] /\left[1+r_{t}\right]<1$. Thus if the price statistician has estimates for the quarter $t$ building services inflation rate $i_{t}$, the quarter $t$ cost of capital $r_{t}$ and an estimate for the per square meter new building construction cost at the beginning of period $t, P_{0}^{t},{ }^{41}$ equation (17) can be used to determine $f^{t}$, the per square meter value of building services for quarter $t$. Now substitute equations (16) into (15) and we obtain the following expression for the beginning of period $t$ asset price $P_{n}^{t}$ of a building of the same type that is $n$ quarters old at the start of period $t$ :

$$
\begin{gathered}
P_{n}^{t}=f^{t}\left[1+\gamma_{t}+\left(\gamma_{t}\right)^{2}+\cdots+\left(\gamma_{t}\right)^{L-(n+1)}\right] ; n=1,2, \ldots, L-1 \\
=f^{t} \cdot \frac{1-\left(\gamma_{t}\right)^{L-n}}{1-\gamma_{t}}
\end{gathered}
$$

where the second equation follows if $\gamma_{t}<1 .{ }^{42}$ Thus if an estimate for the construction cost of a new building

\footnotetext{
${ }^{39}$ As Dixon, Crosby and Law (1999) [22] noted, basically three depreciation models have been considered for commercial structures: declining balance (or geometric) depreciation, straight line depreciation or one hoss shay (or light bulb) depreciation. The problem with the first two depreciation models is that the structure services provided by the building will approach zero as the building nears the end of its life. But even near the end, the structure is still providing basic floor space services that are much the same as the services provided in previous periods. Thus we think that the one hoss shay model of depreciation is more realistic for a single structure than the competing geometric and straight line depreciation models.

${ }^{40}$ It is due to Böhm-Bawerk (1891) [1]. It is described in more detail by Hulten (1990; 124) [30] and Diewert (2005; 506-510) [16]. The name comes from a poem by Oliver Wendell Holmes: “The Deacon's Masterpiece or the Wonderful 'One-Hoss Shay': A Logical Story".

${ }^{41}$ Note that we have made an assumption here that the value of the new building is equal to its construction cost. This assumption is likely to be approximately true but it will generally be only an approximation.

${ }^{42}$ Cross sectional depreciation for a building of age $n$ at the beginning of quarter $t$ is defined as $D_{n}^{t} \equiv P_{n}^{t}-P_{n+1}^{t}$ for $n=0,1,2, \ldots, L-1$. Using the first equation in (18), it can be seen that $D_{n}^{t}=f^{t}\left(\gamma^{t}\right)^{L-(n+1)}$ for $n=0,1,2, \ldots, L-1$. Thus if $\gamma^{t}<1$, cross sectional depreciation increases as the age of the asset increases. However, if $r_{t}=i_{t}=0$, then $\gamma^{t}=1$ and $D_{n}^{t}=f^{t}$ for $n=0,1,2, \ldots, L-1$; i.e., cross sectional depreciation is constant under these conditions and one hoss shay depreciation collapses down to straight line depreciation.
} 
of the type under consideration, $P_{0}^{t}$, is available along with estimates for the expected life of the building $L$, the cost of capital $r_{t}$ and the expected building inflation rate $i_{t}$, then a complete set of flow prices for structure services, $f_{n}^{t}=f^{t}$, and asset prices by age $n$ of the building $P_{n}^{t}$ can be constructed.

We now suppose that we are considering a specific commercial property in quarters $t$ and $t+1$ and the problem is to construct prices and quantities of building services and estimates of the stock value (and price and quantity) of the building for quarters $t$ and $t+1$. Suppose that $P_{0}^{t}$ represents the period $t$ price of a square meter of a newly constructed building at the beginning of quarter $t$ of the type of building under consideration. Let $Q_{B}^{t}$ be the quarter $t$ floor area of the building in square meters. We suppose that the building floor area remains constant from period to period; i.e.,

$$
Q_{B}^{t}=Q_{B} ; \quad t=0,1,2, \ldots, L-1 .
$$

We assume that the price statistician has estimates for the length of life $L$ for the building, for the firm's cost of capital at the beginning of quarter $t, r_{t}$, for expected building construction cost inflation, $i_{t}$, and for the new building cost per meter squared at the beginning of period $t, P_{0}^{t}$, for quarters $t$ and $t+1$. The quarter $t$ and $t+1$ estimated prices of building services are equal to $f^{t}$ and $f^{t+1}$ defined by (20): ${ }^{43}$

$$
f^{t} \equiv P_{0}^{t} \cdot \frac{1-\gamma_{t}}{1-\left(\gamma_{t}\right)^{L}} ; f^{t+1} \equiv P_{0}^{t+1} \cdot \frac{1-\gamma_{t+1}}{1-\left(\gamma_{t+1}\right)^{L}}
$$

The corresponding quarters $t$ and $t+1$ building services quantities, $Q_{B}^{t}$ and $Q_{B}^{t+1}$, are defined by (19); i.e., the quantities are fixed at the number of square meters of floor space, $Q_{B}$. Thus $f^{t}, f^{t+1}, Q_{B}^{t}$ and $Q_{B}^{t+1}$ defined by (19) and (20) are the prices and quantities that can be inserted into an index number formula that aggregates all building inputs into an overall input price index for the services of the building under consideration. This is the type of input index that would be used in studies of the Multifactor Productivity of the commercial property under consideration.

Constructing suitable prices for beginning of quarter $t$ and $t+1$ asset values of the building that can be used in an index number formula is a more difficult task. The estimated asset value of the building at the beginning of quarter $t$ is $P_{n}^{t} Q_{B}^{t}$ where $P_{n}^{t}$ is defined by (18) and $Q_{B}^{t}$ is defined by (19). The estimated asset value of the building at the beginning of quarter $t+1$ is $P_{n+1}^{t+1} Q_{B}^{t+1}$ where $Q_{B}^{t+1}$ is defined by (19) and $P_{n+1}^{t+1}$ is defined as:

$$
\begin{aligned}
P_{n+1}^{t+1}=f^{t+1}\left[1+\gamma_{t+1}\right. & \left.+\left(\gamma_{t+1}\right)^{2}+\cdots+\left(\gamma_{t+1}\right)^{L-(n+2)}\right] ; \quad n=1,2, \ldots, L-1 \\
& =f^{t+1} \cdot \frac{1-\left(\gamma_{t+1}\right)^{L-(n+1)}}{1-\gamma_{t+1}}
\end{aligned}
$$

\footnotetext{
${ }^{43} \mathrm{We}$ are assuming that $\gamma_{t} \equiv\left[1+i_{t}\right] /\left[1+r_{t}\right]<1$ for periods $t$ and $t+1$. Note that if $r_{t}=r_{t+1}$ and $i_{t}=i_{t+1}$, then $\gamma_{t}=\gamma_{t+1}$ and $f^{t+1} / f^{t}=P_{0}^{t+1} / P_{0}^{t}$. Thus if the cost of capital and the expected structure services inflation rate are constant from period to period, the rental price for structure space $f^{t}$ will be proportional to $P_{0}^{t}$, the new construction price index for quarter $t$.
} 
where the second equation in (21) follows if $\gamma_{t+1}<1$. At first glance, it might appear that one could simply use the asset prices $P_{n}^{t}$ and $P_{n+1}^{t+1}$ defined by (18) and (21) and the quantities $Q_{B}^{t}$ and $Q_{B}^{t+1}$ as suitable prices and quantities that could be used in an asset price index number formula. However, this is not a conceptually correct procedure because the quality of the building is not being held constant as we go from period $t$ to period $t+1$. The period $t+1$ building is not the same as a period $t$ building since the older building has one less period left in its expected life ${ }^{44}$ and thus $P_{n+1}^{t+1} / P_{n}^{t}$ does not represent a constant quality asset price index for the building under consideration.

Fortunately, there is a way to overcome the above lack of comparability problem. For each quarter $t$, we can convert the building quantity $Q_{B}^{t}$ into an equivalent number of units of a new building. Thus define the quarter $t$ quality adjusted quantity of building units, $Q_{B}^{t^{*}}$, as follows:

$$
Q_{B}^{t^{*}} \equiv Q_{B}^{t} \cdot \frac{P_{n}^{t}}{P_{0}^{t}}=Q_{B}^{t} \cdot \frac{1-\left(\gamma_{t}\right)^{L-n}}{1-\left(\gamma_{t}\right)^{L}}
$$

where the second equation in (22) follows from the second equations in (17) and (18). The corresponding quarter $t+1$ quality adjusted quantity of building units, $Q_{B}^{t+1^{*}}$, is defined as follows:

$$
Q_{B}^{t+1^{*}} \equiv Q_{B}^{t+1} \cdot \frac{P_{n+1}^{t+1}}{P_{0}^{t+1}}=Q_{B}^{t+1} \cdot \frac{1-\left(\gamma_{t+1}\right)^{L-(n+1)}}{1-\left(\gamma_{t+1}\right)^{L}} .
$$

Thus when constructing a constant quality asset price index for the commercial property under consideration going from quarter $t$ to $t+1$, the new asset building prices $P_{0}^{t}$ and $P_{0}^{t+1}$ can be used in the index number formula along with the quality adjusted building quantities, $Q_{B}^{t^{*}}$ and $Q_{B}^{t+1^{*}}$ defined above by (22) and (23). ${ }^{45}$

There are limitations of our suggested price construction models:

- The estimate for the expected age of the building $L$ will be subject to some uncertainty;

- Similarly, there will be uncertainty about the estimated cost of capital $r_{t}$ and expected building inflation rate $i_{t}$;

- The assumption that depreciation is of the one hoss shay type may not be correct;

- The new building construction price index (in level form) $P_{0}^{t}$ may not be appropriate for the particular building under consideration and

- The assumption that new building value is equal to new building cost may also be only an approximation.

\footnotetext{
${ }^{44} \mathrm{We}$ did not have this problem when constructing a price index for building services since the one hoss shay model of depreciation explicitly assumes that the flow of building services is constant over all ages of the building (until it is retired or demolished).

${ }^{45}$ If $\gamma_{t}=\gamma_{t+1}$, our suggested quality adjustment procedure can be justified using Hicks' Aggregation Theorem: "Thus we have demonstrated mathematically the very important principle, used extensively in the text, that if the prices of a group of goods change in the same proportion, that group of goods behaves just as if it were a single commodity." J.R. Hicks (1946; 312-313) [29]. It is like that $\gamma_{t}$ will be approximately constant going from quarter to quarter since $r_{t}$ and $i_{t}$ are unlikely to change much going from quarter to quarter. If $\gamma_{t}$ is constant over time, it can be seen that the entire schedule of asset prices by age $n$, $P_{n}^{t}$, moves in strict proportion to the movements in $P_{0}^{t}$ over time.
} 
However, it should be noted that national income accountants struggle with the same set of problems when they construct national balance sheet estimates for other components of the capital stock.

There is an alternative way of looking at our suggested method for finding flow of services prices and asset values for the building on the commercial property: our method can simply be regarded as a method for amortizing the initial construction cost of the building. Since amortization models are somewhat arbitrary, the method we have suggested seems to be a "reasonable" method. ${ }^{46}$

In section 2 above, we mentioned how the one hoss shay algebra could be used to impute quarterly revenues for say office space in a building that is leased out to various tenants on long term leases. Now suppose that the entire building is leased out to a single tenant who in turn subleases the space to other tenants or simply uses the building to generate revenues. The structure (and land) services valuation problem for the firm that has leased the entire building is now different from a firm that owns the land (the latter case will be considered in the following section). If the tenant pays a quarterly rent to the firm that owns the building, this rental payment can be considered an intermediate input cost for the leasing firm in the production accounts for the commercial property sector. This quarterly rental payment will appear as a revenue item for the firm that owns the building. This is reasonably straightforward. However, the problem here is do we regard the quantity of the intermediate input (combined structure and land services) for the leasing tenant to be constant over the life of the lease? If so, there is no problem in decomposing the intermediate input payment into price and quantity components over the life of the lease. If the quality of the structure service changes over time (due to changes in maintenance or to improvements in amenities), then there is a problem in quality adjusting the quantity of service over time. There is no easy answer to this quality adjustment problem, and so in practice, it may be necessary to assume that this quality is constant over the life of the lease. However, this is not the end of our measurement problems. Suppose the tenant does not pay quarterly rent over the life of the lease but rather pays a lump sum for the services of the structure over the lifetime of the lease at the beginning of the leasing period. In order to value the input contribution to the single tenant firm of the property over the life of the lease, it is reasonable to use the one hoss shay model explained above to value the long term lease and decompose it into period by period input costs. The value of the lease now covers the combined services of the structure and the land that it sits on for the duration of the lease. ${ }^{47}$ However, note that following the resulting imputed rental prices for the space over time will not give us a reasonable index of current commercial property rents since the sequence of imputed rentals is entirely determined by the initial lease payment, the duration of

\footnotetext{
${ }^{46}$ If commercial properties could be sold as building only sales, then it would be possible to check on the validity of alternative depreciation models using information on sales of commercial properties. However, typically sales of properties include the land that sits under the structure so information on the value of the used structure will be contaminated by the land value of the property.

${ }^{47}$ If the lease payment is made at the beginning of period $t$ and the length of the lease is $L$ quarters, then $P_{0}^{t}$ in equation (13) can be interpreted as the total lease payment, $f^{t}$ is the period $t$ imputed input cost for the structure (with the land), $i_{t}$ is the expected quarterly inflation rate for the rental of space of the type under consideration, $r_{t}$ is the (single) tenant's opportunity cost of capital at the beginning of period $t$ and $\left(1+i_{t}\right)^{s} f^{t}$ is the imputed period $t+s$ input cost for the space under consideration for $s=1,2, \ldots, L-1$. Note that the initial lease payment $P_{0}^{t}$ is now treated as an investment cost by the tenant and hence is amortized over time. This lease payment $P_{0}^{t}$ is also treated as a deferred revenue asset by the firm that owns the building and the owning firm has to amortize this asset over the length of the lease (possibly using a different method of amortization). Accounting for commercial property transactions in the System of National Accounts is not a trivial matter!
} 
the lease and assumptions about interest rates and expected inflation rates made at the beginning of the lease. ${ }^{48}$

We can now suggest a possible treatment of capital expenditures on a commercial property. The same model of depreciation that we have suggested for the original structure can be applied to each capital expenditure. All that is required is an estimate for the length of life for each period's capital expenditure (this will generally be shorter than the length of life $L$ used for the main structure) and an appropriate deflator for these expenditures. The resulting algebra will be messy ${ }^{49}$ but conceptually, there do not seem to be any problems in addition to the problems that have been mentioned for our analysis presented above for the underlying structure.

Now that we have developed price and quantity estimates for structures, we can return to the problem of obtaining price and quantity decompositions for insurance payments and property taxes that fall on structures. We address the insurance problem first.

The main component of property insurance is the protection of the structure from damage due to fire and other causes. An insurance policy on a commercial property could provide a payment in case of the complete destruction of the structure which could either (i) cover the cost of complete replacement of the structure with a new structure of the same type or (ii) cover the value of the depreciated structure. Let $C_{\mathrm{PI}}^{t}$ be the period $t$ value of property insurance payments. Then for case (i), an appropriate period $t$ price of insurance is $p_{\mathrm{PI}}^{t} \equiv C_{\mathrm{PI}}^{t} / Q_{B}^{t}$ and the corresponding quantity of insurance services is $Q_{B}^{t}$, the number of square meters of floor space for the structure in period $t$. For case (ii), the appropriate period $t$ price of insurance is $p_{\mathrm{PI}}^{t^{*}} \equiv C_{\mathrm{PI}}^{t} / Q_{B}^{t^{*}}$ and the corresponding quantity of insurance services is $Q_{B}^{t^{*}}$, the quality adjusted number of square meters of floor space defined above by (22). In both cases, the insurance price is viewed as the per square meter cost of protection of the structure from damage. An implicit assumption for both price treatments is that the risks of damage remain constant over time. ${ }^{50}$

The period $t$ property tax payments, $C_{\mathrm{PT}}^{t}$, can usually be decomposed into two additive components: $C_{\mathrm{PT}}^{t}=C_{\mathrm{ST}}^{t}+C_{\mathrm{LT}}^{t}$ where $C_{\mathrm{ST}}^{t}$ are the period $t$ tax payments that can be attributed to the structure and $C_{\mathrm{LT}}^{t}$ are the payments that can be attributed to the plot of land that the structure is located upon. The tax payments on the structure are almost always assessed on the basis of the current (depreciated) value of the structure. Thus the appropriate price-quantity decomposition of the value of structure tax payments $C_{\mathrm{ST}}^{t}$ is to define the period $t$ price $p_{\mathrm{ST}}^{t}$ and the corresponding quantity $q_{\mathrm{ST}}^{t}$ as follows:

\footnotetext{
${ }^{48}$ Since long term leasing transactions are typically more prevalent than outright sales of commercial properties, it might be thought that a hedonic regression approach to obtaining constant quality price indexes for commercial properties would be more successful than a hedonic regression approach on sales. However, these long term lease transactions are still relatively sparse (since the leases are long term!) and so it will be difficult to find a parsimonious set of characteristics for the leases and the underlying properties that will lead to successful hedonic regressions that have high explanatory power. The advantages of the NOI approach to constructing indexes are: (i) the data are available every quarter for the buildings under consideration and (ii) all of the characteristics of the property are held (approximately) constant from period to period, except for building depreciation. Thus the NOI approach has all of the advantages of the repeat sales method for constructing house price indexes (in terms of holding characteristics to be relatively constant) but has the additional advantage of providing information every quarter.

${ }^{49}$ With one hoss shay depreciation, there will be a separate construction expenditures asset for each time period when a capital expenditure took place and thus as time marches on, there will be more and more construction assets to depreciate and account for.

${ }^{50}$ This assumption is only a useful approximation to reality. Unfortunately, obtaining constant quality prices for property insurance under conditions of changing risk factors is extremely complex; see Diewert (1993; 415-423) [14] (1995) [15].
} 


$$
p_{\mathrm{ST}}^{t} \equiv \frac{C_{\mathrm{ST}}^{t}}{Q_{B}^{t^{*}}} ; q_{\mathrm{ST}}^{t} \equiv Q_{B}^{t^{*}}
$$

where $Q_{B}^{t^{*}}$ is the quality adjusted number of square meters of floor space defined above by (22). An appropriate price-quantity decomposition of the value of land tax payments $C_{\mathrm{LT}}^{t}$ is defined as follows:

$$
p_{\mathrm{LT}}^{t} \equiv \frac{C_{\mathrm{LT}}^{t}}{Q_{L}} ; q_{\mathrm{LT}}^{t} \equiv Q_{L}
$$

where $Q_{L}$ is the size of the property's land area in square meters (which remains constant over the periods $t)$.

What services do property taxes provide to the firm? These payments allow the firm to be in existence and to obtain some specific services from the governments that levy the taxes, such as access to a publically provided road network.

We will not decompose business income taxes into price and quantity components. Instead, we assume that business income taxes are reflected in the beginning of the period cost of financial capital, $r_{t}$; i.e., this rate is approximately equal to the after business tax rate of return that investors require plus the prevailing rate of business income taxation.

We now turn our attention to the final set of problems that are associated with the determination of stock and flow prices for the land plot.

\section{The Construction of Stock and Flow Prices for the Land Area of the Commercial Property}

The starting point of our analysis in this section is the definition of the Net Operating Income $\left(\mathrm{NOI}^{t}\right)$ of the commercial property under consideration for period $t$ :

$$
\mathrm{NOI}^{t} \equiv R^{t}-C^{t}-C_{\mathrm{PI}}^{t}-C_{\mathrm{PT}}^{t} ; \quad t=0,1,2, \ldots, L-1
$$

where $R^{t}$ is the revenue generated by the property in period $t, C^{t}$ is the period $t$ variable cost for the property, $C_{\mathrm{PI}}^{t}$ is the period $t$ cost of property insurance and $C_{\mathrm{PT}}^{t}$ denotes period $t$ property tax payments. ${ }^{51}$ It should be noted that we are basically following the property assessment literature in defining NOI. ${ }^{52}$

Our first task is to determine the period $t$ rents that can be attributed to the land (and of course, the location of the property). We assume that land rents in period $t, \mathrm{LR}^{t}$, are equal to the period $t$ net operating income less our imputed flow of building services, which is equal to the building flow of services price per $m^{2}, f^{t}$, defined in (20) times the building floor space, $Q_{B}^{t}$ :

\footnotetext{
${ }^{51}$ See (1), (10), (24) and (25) for decompositions of $R^{t}, C^{t}, C_{\mathrm{ST}}^{t}$ and $C_{\mathrm{LT}}^{t}$ into price and quantity components where $C_{\mathrm{PT}}^{t}=C_{\mathrm{ST}}^{t}+C_{\mathrm{LT}}^{t}$.

${ }^{52}$ There is some variation across authors in the treatment of property taxes and depreciation: some authors include these items as part of NOI and some do not.
} 


$$
\mathrm{LR}^{t} \equiv \mathrm{NOI}^{t}-f^{t} Q_{B}^{t}
$$

Once total land rents $\mathrm{LR}^{t}$ have been determined by (27), the corresponding constant quality land services price, $p_{L}^{t}$, can be defined by dividing land rents by the area of the property, $Q_{L}^{t}$, which will be constant over $t:$

$$
p_{L}^{t} \equiv \frac{\mathrm{LR}^{t}}{Q_{L}^{t}}
$$

Thus the appropriate decomposition of land rents $\mathrm{LR}^{t}$ into price and quantity components, is given by (28); i.e., $\mathrm{LR}^{t}=p_{L}^{t} Q_{L}^{t}$. Finally, if an index of structure and land service flows for the property is required, then one should choose an appropriate bilateral index number formula for prices, such as the Fisher price index $P_{F}$, and then calculate the aggregate service flow price change for the property going from period $t$ to $t+1$ as $P_{F}\left(f^{t}, p_{L}^{t} ; f^{t+1}, p_{L}^{t+1} ; Q_{B}^{t}, Q_{L}^{t} ; Q_{B}^{t+1}, Q_{L}^{t+1}\right) .^{53}$

The above material completes our discussion of how to account for the valuation of input and output flows for the commercial property. There is only one remaining valuation problem and that is to obtain an asset or stock price for land at the beginning of each period.

Consider first the valuation of the property at the beginning of period $t$. The period $t$ land rent per $m^{2}$ is $p_{L}^{t}$. Assume a constant land rent inflation rate equal to $i_{L}^{t}$ and assume that the land rent accrues at the end of each period. As in the previous section, assume that the firm's beginning of period $t$ cost of capital is $r_{t}$ and this rate is expected to persist into the future. Then the discounted (to the beginning of period $t$ ) stream of expected land rents per $m^{2}$ is an approximation to the beginning of period t asset price of land, $P_{L}^{t}$. We use this approximation and define $P_{L}^{t}$ as follows: ${ }^{54}$

$$
\begin{gathered}
P_{L}^{t} \equiv\left(1+r_{t}\right)^{-1} p_{L}^{t}\left[1+\gamma_{L}+\left(\gamma_{L}\right)^{2}+\left(\gamma_{L}\right)^{3}+\cdots\right] \\
=\left(1+r_{t}\right)^{-1} p_{L}^{t}\left(1-\gamma_{L}\right)^{-1} \\
=\frac{p_{L}^{t}}{r_{t}-i_{L}^{t}}
\end{gathered}
$$

where $\gamma_{L} \equiv\left(1+i_{L}^{t}\right) /\left(1+r_{t}\right)$ and we assume that $\gamma_{L}<1$ so that the period $t$ cost of capital $r_{t}$ is greater than the period $t$ expected land rent inflation rate $i_{L}^{t}$. Thus the product of $P_{L}^{t}$ defined by (29) and the plot area $Q_{L}^{t}=Q_{L}$ provide a price and quantity decomposition for the beginning of period $t$ asset value of the land area of the commercial property.

\footnotetext{
${ }^{53}$ Since quantities are constant over the two periods (so $Q_{B}^{t}=Q_{B}^{t+1}=Q_{B}$ and $Q_{L}^{t}=Q_{L}^{t+1}=Q_{L}$ ), the Fisher, Laspeyres and Paasche price indexes will all equal $\left[f^{t+1} Q_{B}+p_{L}^{t+1} Q_{L}\right] /\left[f^{t} Q_{B}+p_{L}^{t} Q_{L}\right]$.

${ }^{54}$ There is an implicit assumption that when the current building is retired, it is replaced with a new building with the same floor area.
} 
Finally, if a volume index for the structure and the associated land for the property is required, then Fisher price and quantity indexes for the period $t$ to $t+1$ movements in asset prices and quantities can be constructed. The period $t$ asset value for the property is $P_{0}^{t} Q_{B}^{t^{*}}+P_{L}^{t} Q_{L}^{t}$, and the period $t+1$ asset value is $P_{0}^{t+1} Q_{B}^{t++^{*}}+P_{L}^{t+1} Q_{L}^{t+1}$ where $Q_{L}^{t}=Q_{L}^{t+1}$ and these price and quantity components can be used in the chosen index number formulae.

\section{Conclusion}

The paper briefly reviewed existing methods for constructing commercial property price indexes and found that the capitalization of Net Operating Income seemed to be the most promising method. The details of the method were developed in sections 2-5. The method depends on regular accounting information on commercial properties that consist of a single property, assumptions about the length of life of the structure, a new construction price index for the type of structure under consideration, the firm's cost of raising financial capital and assumptions about expected structure and land inflation rates. Since the amount of land is fixed from period to period and the structure does not change from period to period (except for depreciation and capital expenditures), it is not necessary to collect information on the other characteristics of the property (they will remain roughly constant from period to period). Thus our suggested methodology, while not without problems, seems to be a viable way forward. ${ }^{55}$

We conclude with a note on a weakness of our suggested method for constructing land and structure indexes for commercial properties: the method is dependent on the availability of quarterly accounting data on a sample of commercial properties on a timely basis. But accounting data for a property for the current quarter will only be available with a lag and hence our suggested method will not be able to construct the required indexes in a timely manner. In order to deal with this problem, we suggest the construction of provisional indexes that would be revised as accounting information became available. In order to construct these provisional indexes for structure and land services, two additional price indexes would need to be constructed:

An index of commercial property rents for the type of property under consideration, say $\rho^{t}$ for quarter $t$ and A price index for intermediate and labour input costs for the owners of properties of the type under consideration, say $\rho_{I}^{t}$ for quarter $t$.

Recall that in section 2 above, we assumed that the quarter $t$ revenue for a property where accounting data were available was $R^{t} \equiv \sum_{n=1}^{N} p_{n}^{t} q_{n}^{t} \equiv \mathbf{p}^{t} \cdot \mathbf{q}^{t}$. When constructing an interim revenue estimate for the property, we suggest estimating the quarter $t+1$ revenue for the property as $R^{t+1^{*}} \equiv R^{t}\left[\rho^{t+1} / \rho^{t}\right] .{ }^{56}$ Similarly, in section 3 above, we assumed that the quarter $t$ variable input cost for a property where

\footnotetext{
${ }^{55}$ We note that our approach to capitalizing the land rent is similar to the capitalization of NOI methodology that is commonly used in making property appraisals. Thus Baum and Crosby $(2008 ; 125)$ [2] suggest that an estimate for the value of a property is the current NOI of the property divided by their suggested capitalization rate $k \equiv r-g+d$, where $r$ is the required rate of return (which includes a risk premium), $g$ is the expected rate of growth in rental prices (the counterpart to our $i$ ) and $d$ is the expected depreciation rate. Baum and Crosby $(2008 ; 71)$ [2] explain how they introduced depreciation into their income capitalization formula as follows: "As a result of depreciationn, rental values may be rising as a combined result of market rental growth tempered by depreciation, at a rate of $(1+g) /(1+d)$, where $g$ is the annual rate of rental growth for new buildings and $d$ is the annual rate of depreciation." The problem with this approach to depreciation is that it will only be valid if the property's land to rentable floor space area is approximately constant across properties.

${ }^{56}$ If there is evidence that vacancy rates for the property type under consideration have changed, then it may be appropriate to further adjust $R^{t+1^{*}}$ by the change in vacancy rate.
} 
accounting data were available was $C^{t} \equiv \sum_{m=1}^{M} p_{I m}^{t} q_{I m}^{t} \equiv \mathbf{p}_{I}^{t} \cdot \mathbf{q}_{I}^{t}$. When constructing an interim variable input cost estimate for the property, we suggest estimating the quarter $t+1$ variable input cost as $C^{t+1^{*}} \equiv C^{t}\left[\rho_{I}^{t+1} / \rho_{I}^{t}\right]$. The analysis presented in section 4 regarding the construction of structure stock and flow prices remains unchanged. However, the analysis presented in section 5 does change when constructing the interim indexes for land: equation (26) for quarter $t+1$ is replaced by the following equation which defines estimated Net Operating Income for the property, $\mathrm{NOI}^{t+1^{*}}$ :

$$
\mathrm{NOI}^{t+1^{*}} \equiv R^{t+1^{*}}-C^{t+1^{*}}-C_{\mathrm{PI}}^{t+1}-C_{\mathrm{PT}}^{t+1} ; \quad t=0,1,2, \ldots, L-1 .
$$

The remainder of the methodology presented in section 5 can be carried out using the preliminary estimate for Net Operating Income for quarter $t+1$ defined above. Once the accounting information for quarter $t+1$ for the property becomes available, the analysis can be redone as indicated in section 5. Obviously this methodological approach is not suitable for the construction of an index that cannot be revised but when constructing price and quantity indexes for components of the national accounts, it is normal to revise the indexes when additional information becomes available,

\section{References}

Böhm-Bawerk, E. V. (1891), The Positive Theory of Capital, W. Smart (translator of the original German book published in 1888), New York: G.E. Stechert.

Baum, A. and N. Crosby (2008), Property Investment Appraisal, 3rd Edition, Oxford: Blackwell.

Bokhari, S and D. Geltner (2012), "Estimating Real Estate Price Movements for High Frequency Tradable Indexes in a Scarce Data Environment", Journal of Real Estate Finance and Economics, 45:2, 522-543.

Christensen, L.R. and D.W. Jorgenson (1969), “The Measurement of U.S. Real Capital Input, 1929-1967”, Review of Income and Wealth 15, 293-320.

Christensen, L.R. and D.W. Jorgenson (1973), "Measuring the Performance of the Private Sector of the U.S. Economy, 1929-1969", pp. 233-351 in Measuring Economic and Social Performance, M. Moss (ed.), New York: Columbia University Press.

Crosby, N., S. Devaney and V. Law (2012), "Rental Depreciation and Capital Expenditure in the UK Commercial Real Estate Market, 1993-2009”, Journal of Property Research 29:3, 227-246.

Davies, G.R. (1924), "The Problem of a Standard Index Number Formula”, Journal of the American Statistical Association 19, 180-188.

de Haan, Jan and W.E. Diewert (eds.) (2011), Residential Property Price Handbook, Luxembourg: Eurostat, November 8 version. http://epp.eurostat.ec.europa.eu/portal/page/portal/hicp/methodology/hps/ rppi handbook

Deng, Y., D.P. McMillen and T.F. Sing (2013), "Matching Indices for Thinly-Traded Commercial Real Estate in Singapore", Department of Real Estate and Institute of Real Estate Studies, National University of Singapore, 21 Heng Mui Keng Terrace, \#04-02, Singapore, 119613

Devaney, S. and R. M. Diaz (2010), "Transaction Based Indices for the UK Commercial Property Market: Exploration and Evaluation Using IPD Data", University of Aberdeen Business School, Discussion Paper 2010-02.

Diewert, W.E. (1978), “Superlative Index Numbers and Consistency in Aggregation”, Econometrica 46, 883-900.

Diewert, W.E. (1980), “Aggregation Problems in the Measurement of Capital”, pp.433-528 in The Measurement of Capital, edited by D. Usher, Studies in Income and Wealth, Vol. 45, National Bureau of Economics Research, University of Chicago Press, Chicago.

Diewert, W.E. (1992), “The Measurement of Productivity”, Bulletin of Economic Research 44, 165-198.

Diewert, W.E. (1993), "Symmetric Means and Choice Under Uncertainty", pp. 355-433 in Essays in Index Number Theory, Volume I, W.E. Diewert and A.O. Nakamura (eds.), Amsterdam: North Holland, (1993), pp. 355-433.

Diewert, W.E. (1995), "Functional Form Problems in Modeling Insurance and Gambling", The Geneva Papers on Risk and 
Insurance Theory 20, 135-150.

Diewert, W.E. (2005), "Issues in the Measurement of Capital Services, Depreciation, Asset Price Changes and Interest Rates", pp. 479-542 in Measuring Capital in the New Economy, C. Corrado, J. Haltiwanger and D. Sichel (eds.), Chicago: University of Chicago Press.

Diewert, W.E. (2010), “Alternative Approaches to Measuring House Price Inflation”, Discussion Paper 10-10, Department of Economics, The University of British Columbia, Vancouver, Canada, V6T 1 Z1.

Diewert, W.E. (2011), “The Paris OECD-IMF Workshop on Real Estate Price Indexes: Conclusions and Further Directions”, pp. 87-116 in Price and Productivity Measurement, Volume 1, Housing, W.E. Diewert, B.M. Balk, D. Fixler, K.J. Fox and A.O. Nakamura (eds.), Trafford Publishing.

Diewert, W.E. (2012), Consumer Price Statistics in the UK, Government Buildings, Cardiff Road, Newport, UK, NP10 8XG: Office for National Statistics.

Diewert, W.E. and D.A. Lawrence (2000), "Progress in Measuring the Price and Quantity of Capital", pp. 273-326 in Econometrics and the Cost of Capital: Essays in Honor of Dale W. Jorgenson, L.J. Lau (ed.), Cambridge MA: The MIT Press.

Diewert, W.E., A.O. Nakamura and L.I. Nakamura (2009), "The housing bubble and a new approach to accounting for housing in a CPI”, Journal of Housing Economics 18:3, 156-171.

Dixon, T.J., N. Crosby and V.K. Law (1999), “A Critical Review of Methodologies for Measuring Rental Depreciation Applied to UK Commercial Real Estate”, Journal of Property Research 16:2, 153-180.

Feenstra, R.C. and W.E. Diewert (2001), "Imputation and Price Indexes: Theory and Evidence from the International Price Program”, Discussion paper 01-10, The Department of Economics, The University of British Columbia, Vancouver Canada, V6T 1Z1. http://faculty.arts.ubc.ca/ediewert/dp0110.pdf

Fisher, I. (1911), The Purchasing Power of Money, London: Macmillan.

Fisher, I. (1922), The Making of Index Numbers, Boston: Houghton-Mifflin.

Fisher, J., D. Geltner, and R.B. Webb (1994), "Value Indices of Commercial Real Estate: A Comparison of Index Construction Methods", Journal of Real Estate Finance and Economics 9, 137-164.

Geltner, D. (1997), The Use of Appraisals in Portfolio Valuation and Index Construction, Journal of Property Valuation and Investment $15,423-448$.

Geltner, D., H. Pollakowski, H. Horrigan, and B. Case (2010), "REIT-Based Pure Property Return Indexes", United States Patent Application Publication, Publication Number: US 2010/0174663 A1, Publication Date: July 8, 2010.

Hicks, J.R. (1946), Value and Capital, Second Edition, Oxford: Claredon Press.

Hulten, C.R. (1990), "The Measurement of Capital”, pp. 119-152 in Fifty Years of Economic Measurement, E.R. Berndt and J.E. Triplett (eds.), Studies in Income and Wealth, Volume 54, The National Bureau of Economic Research, Chicago: The University of Chicago Press.

ILO/IMF/OECD/UNECE/Eurostat/The World Bank (2004), Consumer Price Index Manual: Theory and Practice, Peter Hill (ed.), Geneva: International Labour Office.

IMF/ILO/OECD/UNECE/Eurostat/The World Bank (2004), Producer Price Index Manual: Theory and Practice, Paul Armknecht (ed.), Washington D.C.: International Monetary Fund.

Jorgenson, D.W. (1963), “Capital Theory and Investment Behaviour”, American Economic Review 53:2, 247-259.

Jorgenson, D.W. (1989), “Capital as a Factor of Production”, pp. 1-35 in Technology and Capital Formation, D.W. Jorgenson and R. Landau (eds.), Cambridge MA: The MIT Press.

Jorgenson, D.W. and Z. Griliches (1967), "The Explanation of Productivity Change", The Review of Economic Studies 34, 249-283.

Laspeyres, E. (1871), “Die Berechnung einer mittleren Waarenpreissteigerung”, Jahrbücher für Nationalökonomie und Statistik $16,296-314$.

Lowe, J. (1823), The Present State of England in Regard to Agriculture, Trade and Finance, second edition, London: Longman, Hurst, Rees, Orme and Brown.

Paasche, H. (1874), "Über die Preisentwicklung der letzten Jahre nach den Hamburger Borsennotirungen”, Jahrbücher für Nationalökonomie und Statistik 12, 168-178.

Schreyer, P. (2001), OECD Productivity Manual: A Guide to the Measurement of Industry-Level and Aggregate Productivity Growth, Paris: OECD.

Schreyer, P. (2009a), Measuring Capital, Statistics Directorate, National Accounts, STD/NAD(2009)1, Paris: OECD. 
Schreyer, P. (2009b), "User Costs and Bubbles in Land Markets", Journal of Housing Economics 18:3, $267-272$.

Shimizu, C., W.E. Diewert, K.G. Nishimura and T. Watanabe (2013), "Estimating Quality Adjusted Commercial Property Price Indexes Using Japanese REIT Data" Center for Advanced Research in Finance (CARF) Working Paper F-307, University of Tokyo. http://www.carf.e.u-tokyo.ac.jp/workingpaper/index.cgi

Shimizu, C., K.G. Nishimura and T. Watanabe (2010), "House Prices in Tokyo: A Comparison of Repeat-Sales and Hedonic Measures", Journal of Economics and Statistics, 230, 792-813.

Theil, H. (1967), Economics and Information Theory, Amsterdam: North-Holland Publishing.

Walras, L. (1954), Elements of Pure Economics, a translation by W. Jaffé of the Edition Définitive (1926) of the Eléments d'économie pure, first edition published in 1874, Homewood, Illinois: Richard D. Irwin.

Walsh, C.M. (1901), The Measurement of General Exchange Value, New York: Macmillan and Co. 